\title{
Levantamento etnobotânico de plantas medicinais em área de caatinga no município de São José de Espinharas, Paraíba, Brasil
}

\author{
MARINHO, M.G.V. ${ }^{*} ;$ SILVA, C.C. ${ }^{2}$; ANDRADE, L.H.C. ${ }^{3}$
}

'UFCG, Unidade Acadêmica de Ciências Biológicas, '2Unidade Acadêmica de Engenheira Florestal, Rodovia Patos/ Teixeira, Bairro Jatobá, CEP:58704-330, Patos-Brasil *mgvmarinho@bol.com.br³FPE, Departamento de Botânica, Avenida Prof. Nelson Chaves S/N, Cidade Universitária, CEP:50372-970, Recife-Brasil Ihcandrade@hotmail.com

\begin{abstract}
RESUMO: Este trabalho teve como objetivo realizar levantamento das plantas medicinais utilizadas pela comunidade de São José de Espinharas, a fim de registrar e preservar o conhecimento popular. A metodologia usada foi de entrevistas semi-estruturadas, com observações participantes, coleta e identificação do material botânico e preparação de exsicatas, resultando em lista de 82 espécies de 38 famílias diferentes. São fornecidas as informações nomenclatura popular e botânica, uso terapêutico, parte utilizada, forma de uso, modo de preparo e doenças tratadas. As raízes $(30 \%)$ foram ás partes mais utilizadas e a forma de preparo foi lambedor (32\%). O conhecimento sobre os usos e modos de preparo provém em geral, dos familiares (85\%). Com esses resultados, verifica-se a interação da população local com a flora e utilização relacionada a aspectos sociais, econômicos, culturais e às mudanças ambientais.
\end{abstract}

Palavras-chave: medicina tradicional, medicina herbária, São José de Espinharas, Paraíba

\begin{abstract}
ABSRACT: Ethnobotanical survey of medicinal plants in a caatinga area in São José de Espinharas Municipality, Paraíba State, Brazil. The aim of this study was to perform a survey of medicinal plants used by the community of São José de Espinharas, Paraíba State, Brazil, in order to record and preserve the folk knowledge. The adopted methodology was based on semistructured interviews, with participating observations, botanical material collection and identification, and voucher preparation, resulting in a list of 82 species of 38 different families. The following information was provided: folk and botanical nomenclature, therapeutic application, used plant part, forms of use, method of preparation and treated diseases. Roots (30\%) constituted the part most frequently used and syrup (32\%) was the predominant method of preparation. The knowledge of uses and methods of preparation are generally handed down in the family (85\%). Based on those results, there is an interaction of the local population with the flora and its use is related to social, economical and cultural aspects and environmental changes.
\end{abstract}

Key words: traditional medicine, herbal medicine, São José de Espinharas, Paraíba

\section{INTRODUÇÃO}

É através da Etnobotânica que se busca o conhecimento e o resgate do saber botânico tradicional, particularmente relacionada ao uso dos recursos da flora.

Segundo Albuquerque (2002), todas as ciências que se ocupam de investigar a relação pessoas/plantas estão preocupadas em registrar e conhecer as estratégias e conhecimentos dos povos locais, procurando também usar essa informação em benefício dessas pessoas.

Nesse contexto, os estudos relacionados com a medicina popular têm merecido cada vez maior atenção, em virtude da gama de informações e esclarecimento à ciência (Sheldon et al., 1997). Assim, esses estudos constituem-se de fundamental importância para o aprimoramento dos conhecimentos acerca do uso de plantas no tratamento de doenças que acometem as populações, aqui em especial, aquelas populações instaladas no domínio do semiárido paraibano.

Para o estado da Paraíba, os estudos etnobotânicos ainda são escassos, apesar de haverem

Recebido para publicação em 01/08/2009

Aceito para publicação em 19/05/2010

Rev. Bras. PI. Med., Botucatu, v.13, n.2, p.170-182, 2011. 
esforços nesse sentido. Albuquerque \& Andrade (2002) ressaltaram que ecossistemas como Mata Atlântica e Caatinga são ainda pobres em investigação da relação seres humanos/natureza.

Nesse sentido, o presente trabalho teve por objetivos (a) realizar o levantamento das plantas medicinais utilizadas no município de São José de Espinharas, Paraíba, no Nordeste brasileiro e (b) caracterizar o uso dessas plantas pela população local.

\section{MATERIAL E MÉTODO}

\section{Caracterização da área de estudo}

O Município de São José de Espinharas está situado na Mesorregião do Sertão Paraibano e na Microrregião da Depressão do Alto Piranhas, São José de Espinharas, com área de $763 \mathrm{Km}^{2}$ (Figura 1) e a $316 \mathrm{Km}$ da capital João Pessoa. Está posicionada geograficamente entre as coordenadas 605'53" de latitude e 37ํ19'35" de longitude oeste (IBGE 1997a).

Clima megatérmico, de tipo tropical, muito quente, e semi-árido, sendo um dos mais secos da região Nordeste do Brasil. Temperatura oscilando entre $28^{\circ} \mathrm{C}$ e $33^{\circ} \mathrm{C}$, máximas absolutas superiores a $35^{\circ} \mathrm{C}$ não são muito comuns. A precipitação pluviométrica média anual é bastante baixa, geralmente entre 500 e $750 \mathrm{~mm}$, sendo mal distribuída ao longo do ano, além da frequência ser irregular (IBGE,1997).

\section{Procedimentos de campo e de laboratório}

Os trabalhos de campo foram conduzidos no período compreendido entre setembro de 2000 a junho de 2002, com coletas botânicas e entrevistas mensais. Foram amostradas as plantas utilizadas como medicinais pelos moradores da área estudada; incluíram-se os espaços urbanos e rurais frase sem sentido. Foram feitas coletas e entrevistas semiestruturadas em cada residência e todas as espécies referidas como medicinais na área de estudo, foram amostradas. Ainda em campo, os espécimes eram fotografados e para cada planta coletada anotaramse em caderneta informações relevantes para o reconhecimento das espécies (hábito, altura, presença/ausência de exsudato, cor do cálice e corola, dos estames e frutos), além de dados referentes a(s) parte(s) utilizada(s) da planta, respectivas finalidades e procedência (espontânea, subespotânea, cultivada em quintais, pomares ou roças, além das comercializadas em feira livres).

A coleta do material botânico foi realizada no momento e após as entrevistas, com a obtenção das partes vegetativas e, quando possível, das reprodutivas. As coletas foram efetuadas nos quintais ou locais próximos às casas dos informantes durante proveitosas caminhadas realizadas em companhia dos mesmos, de acordo com as recomendações de
Martin (1995). A seguir, as amostras foram secas em estufa a $60^{\circ} \mathrm{C}$, posteriormente montado e etiquetado, seguindo-se as técnicas usuais para herborização encontradas em Forman \& Bridson (1989). As exsicatas encontram-se depositadas no Herbário Lauro Pires Xavier (JPB) da Universidade Federal da Paraíba, com duplicatas no herbário Geraldo Mariz
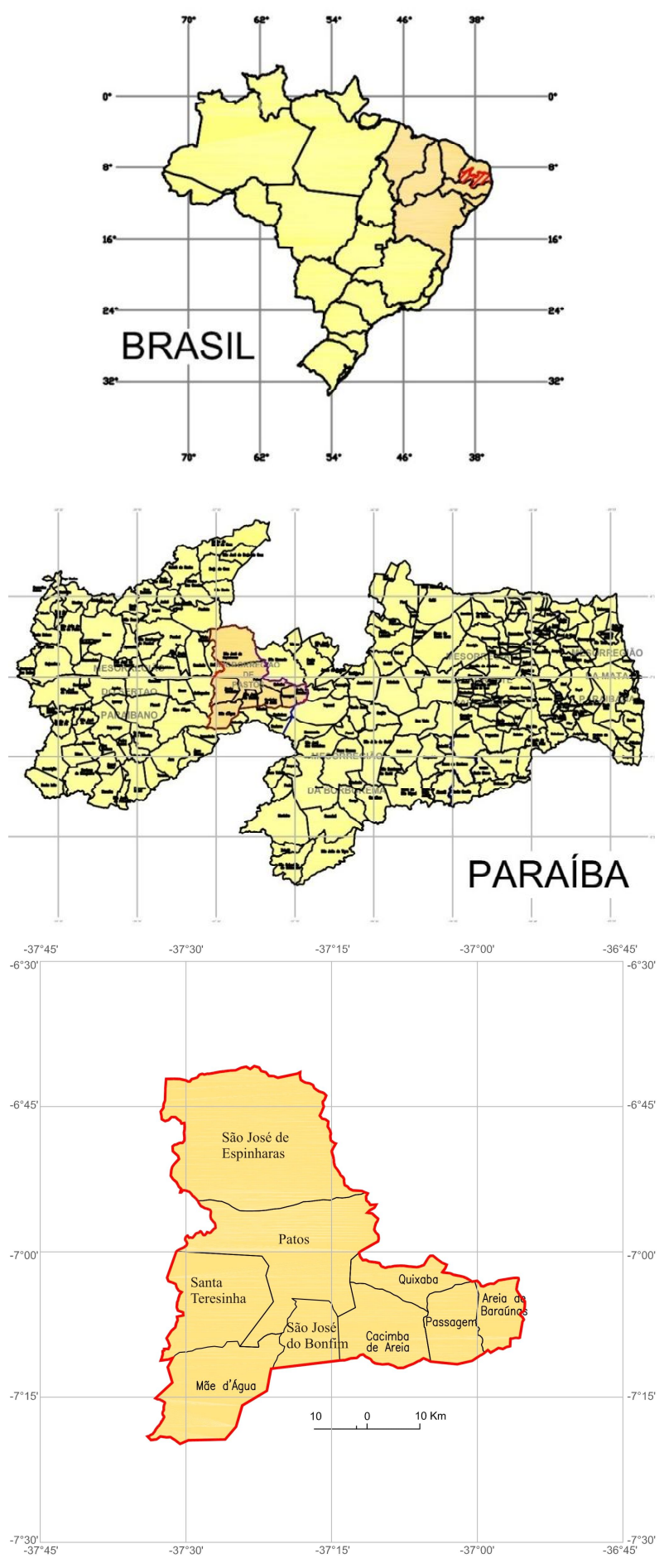

FIGURA 1. Local de trabalho. Município de São José de Espinharas, Estado da Paraíba, nordeste do Brasil. 
(UFP) da Universidade Federal de Pernambuco.

Os estudos morfológicos foram realizados para identificação das espécies com auxílio de chaves analíticas e diagnoses encontradas na bibliografia e por comparação com espécimes já identificados por especialistas. Também se realizou análise comparativa com os trabalhos de Agra (1980); Agra et al. (1994; 1996); Corrêa (1926; 1978); Lorenzi (1992; 1994; 1998); Lorenzi \& Sousa (1995); Matos (1997; 1998).

Visando coletar os dados etnobotânicos acerca das formas de uso das plantas medicinais foram distribuídos 20 questionários, sendo, nove para os informantes da área urbana e onze da rural, representadas por mulheres e homens na faixa etária compreendida entre 20-50 anos.

As informações obtidas desses informantes referiam-se às indicações terapêuticas e as formas de utilizações mais freqüentes dessas espécies. As indicações terapêuticas foram listadas de acordo com o relato dos entrevistados, e fornecidas segundo ordem de registro de coleta, sendo a terminologia empregada para designar as afecções e patologias baseada no relato dos informantes.

Um checklist foi elaborado contendo nomes científicos e vulgares, bem como finalidades terapêuticas, formas de uso, parte(s) utilizada(s) e indicação das espécies mencionadas pelos informantes locais. As famílias, gêneros e espécies encontram-se dispostas ordem alfabética.

\section{RESULTADO E DISCUSSÃO}

Faixa etária e sexo dos informantes: Em São José de Espinharas a idade dos informantes variou de 30 a 60 anos, com $50 \%$ acima de 50 anos, mostrando a importância dessa faixa etária no domínio desse tipo de conhecimento. O maior número de entrevistados pertence ao sexo feminino (70\%) (Figura2).

Tempo de residência no local: Como mostra a Figura 3, o tempo de residência dos informantes no local variou de 10 a 66 anos, sendo que a maioria nasceu nos sítios.

Segundo Amorozo (1996), o tempo durante o qual uma determinada sociedade ocupa um ambiente é muito importante para estabelecer o nível de precisão e profundidade do conhecimento das plantas medicinais com propriedades terapêuticas. Como em outros municípios do sertão paraibano, em São José de Espinharas os mais antigos permanecem e os mais jovens saem para completar os estudos ou a trabalho, evidenciando que, $25 \%$ dos informantes vivem a muitos anos no local (Figura 3).

Grau de instrução e religião: Os dados acerca de alfabetização dos entrevistados indicaram que $40 \%$ são analfabetos, $25 \%$ não são alfabetizados

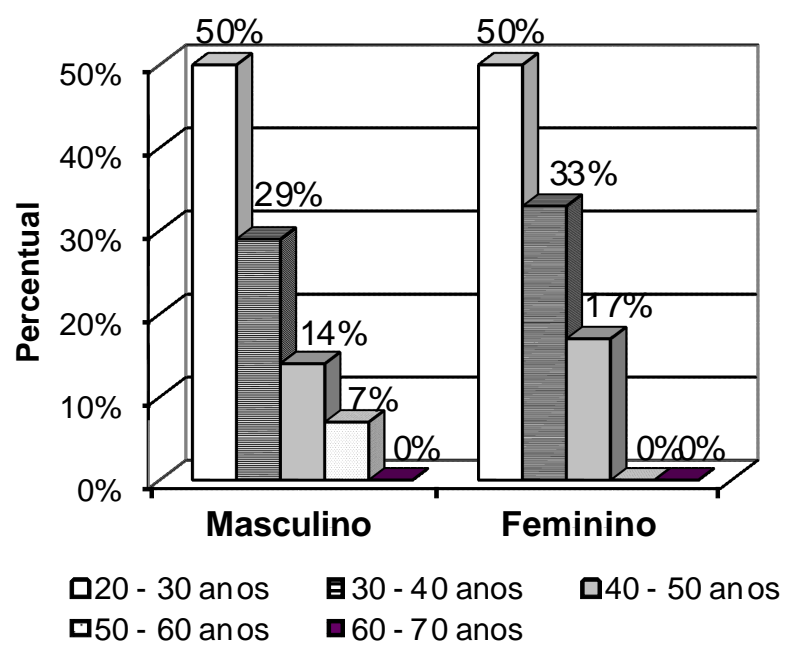

FIGURA 2. Distribuição por gênero e faixa etária dos informantes de São José de Espinharas - PB.

e $30 \%$ sabem ler e escrever pouco, enquanto $5 \%$ sabem apenas assinar o nome (Figura 4).

Os dados obtidos junto à comunidade mostram que o índice de analfabetismo é maior em pessoas de maior idade (Figura 4). Segundo Ming \& Amaral Junior (1995), isso pode colaborar na consolidação de processos de repasse de informações pela via escrita, aumentando a abrangência e eficiência das informações,

Aprendizado sobre o uso das plantas: Segundo Diegues (1996) apud Guarim Neto et al. (2000), o uso dos recursos vegetais está fortemente presente na cultura popular que é transmitida de pais para filhos no decorrer da existência humana. Este conhecimento é encontrado junto a populações tradicionais e/ou contemporâneas e pelo que se tem observado, tende à redução ou mesmo ao desaparecimento, quando sofre a ação inexorável da modernidade.

A maioria dos entrevistados (85\%) afirmou que $\mathrm{o}$ aprendizado sobre $\mathrm{o}$ uso das plantas medicinais foi adquirido por intermédio dos pais (Figura 5). Pela análise das entrevistas foi constatado que quase todas

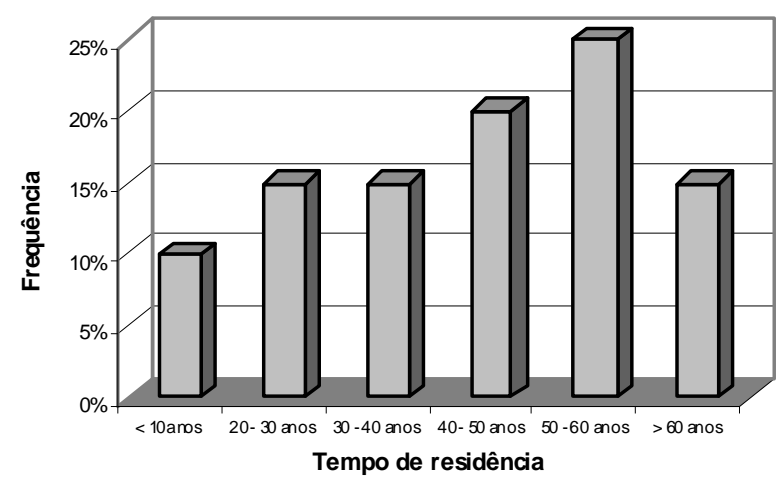

FIGURA 3. Distribuição dos informantes por tempo de residência em São José de Espinharas - PB. 


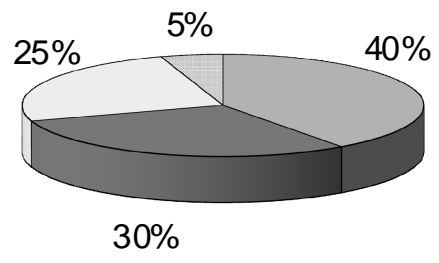

口Não sabe ler, nem escrever

पSabe ler e escrever

凹Sabe apenas assinar o nome

FIGURA 4. Representação percentual do grau de instrução dos informantes de São José de EspinharasPB.

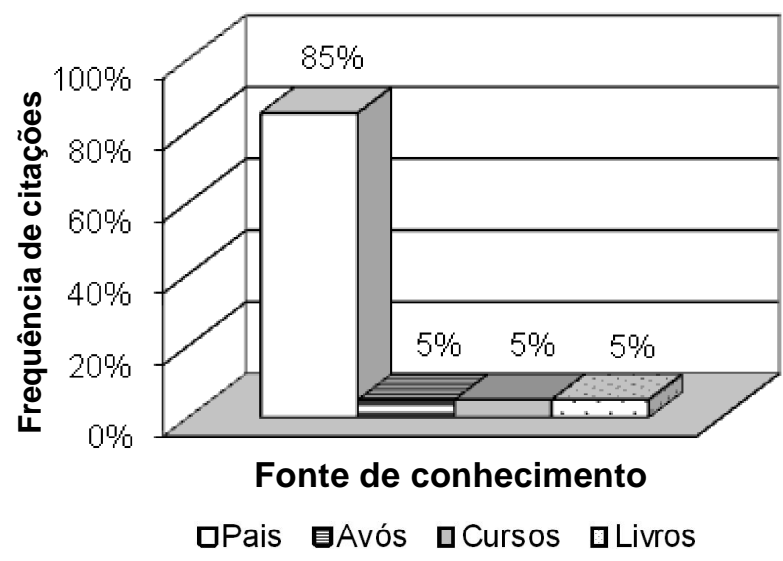

FIGURA 5. Herança de conhecimento das espécies de plantas medicinais dos informantes de São José de Espinharas - PB.

as pessoas que moram na zona urbana pertencem à Pastoral da Criança, têm acesso a palestras, cursos ou outras fontes de informações sobre plantas medicinais. De acordo com Dorigoni et al. (2001), a eficácia das plantas medicinais no tratamento de diversas doenças e o conhecimento sobre o uso e preparo, transmitida de geração em geração de forma empírica, contribui para a grande utilização por populações tradicionais. A geração anterior, nas comunidades estudadas, como ainda não mantinha maiores contatos com o atendimento primário de saúde da rede pública, tinha maior necessidade de uso de produtos da floresta (Caatinga).

Todos os entrevistados também afirmaram, sem precisar a idade, que desde criança ou "desde que me conheço por gente", iniciaram a observação e o uso das plantas medicinais.

Tempo de uso de plantas medicinais: $A$ maioria $(50 \%)$ dos informantes usa plantas medicinais há pelo menos 40 anos, seguido do uso a mais de 60 anos (20\%) (Figura 6). São poucos os informantes que nunca utilizaram plantas medicinais. Desse modo a comunidade estudada utiliza a fitoterapia como forma de curar muitas doenças e usam as plantas medicinais tanto para prevenção como por costume.
Partes da planta utilizada nas preparações: Em relação à preparação dos remédios caseiros as partes das plantas citadas foram raiz, casca do caule, folha, flor, fruto e semente. Embora folhas (27\%) e raízes (19\%) sejam muito utilizadas, nas preparações dos remédios caseiros há predomínio da utilização das cascas do caule (38\%), preparadas sob a forma de decocção e infusão, para uso interno (Figura 7).

Modo de preparo dos remédios caseiros:

Os informantes indicaram diversas formas de preparo dos remédios caseiros, como lambedor (xarope caseiro), chás por decocção e infusão, macerado em água, álcool, cachaça e vinho, banho de assento, compressas e outros. Verificou-se índice mais elevado para preparação na forma de lambedor (32\%), seguido de chá (24\%) (Figura 8).

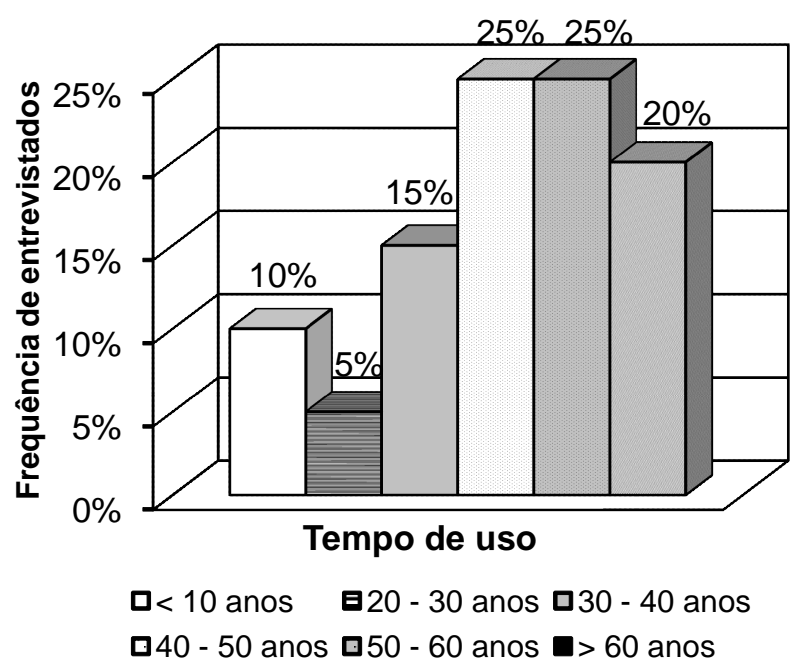

FIGURA6. Tempo de uso de plantas medicinais pelos informantes de São José de Espinharas - PB.

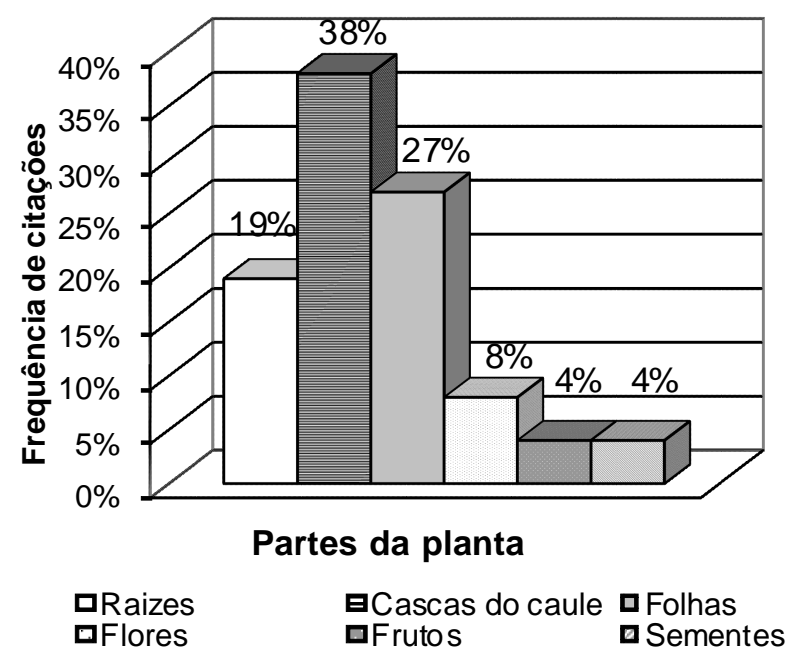

FIGURA 7. Partes da planta utilizadas nas preparações das espécies medicinais no município de São José de Espinharas - PB. 
Obtenção das plantas: A população tem livre acesso às plantas, pois $54 \%$ destes produtos provém da mata (Figura 9) e 23\% é cultivada em casa ou em horto.

\section{informantes}

Espécies de uso medicinais citadas pelos

Foram citadas 82 espécies, pertencentes a 38 famílias botânicas (Tabela 1). A maioria das espécies é nativa (se refere a maioria) da caatinga (54\%) e $23 \%$ são cultivadas em quintais. Isso indica continuado processo de domesticação de plantas pela comunidade, em diversas formas de estágios. $O$ processo de conhecimento e aproveitamento dos recursos genéticos vegetais da caatinga é confirmado pelo maior número de plantas nativas utilizadas. $\mathrm{O}$ quintal é o local onde a comunidade cultiva as espécies de uso mais comum e também aquelas espécies de outras localidades; plantas e receitas são trocadas livremente entre vizinhos e parentes quando há necessidade, reforçando laços sociais e contribuindo para o consenso cultural, conforme é também relatado por Amorozo (1996).

Os nomes científicos e populares das espécies, com as respectivas famílias, citados pelos informantes da comunidade de São José de Espinharas, estão listadas na Tabela 1.

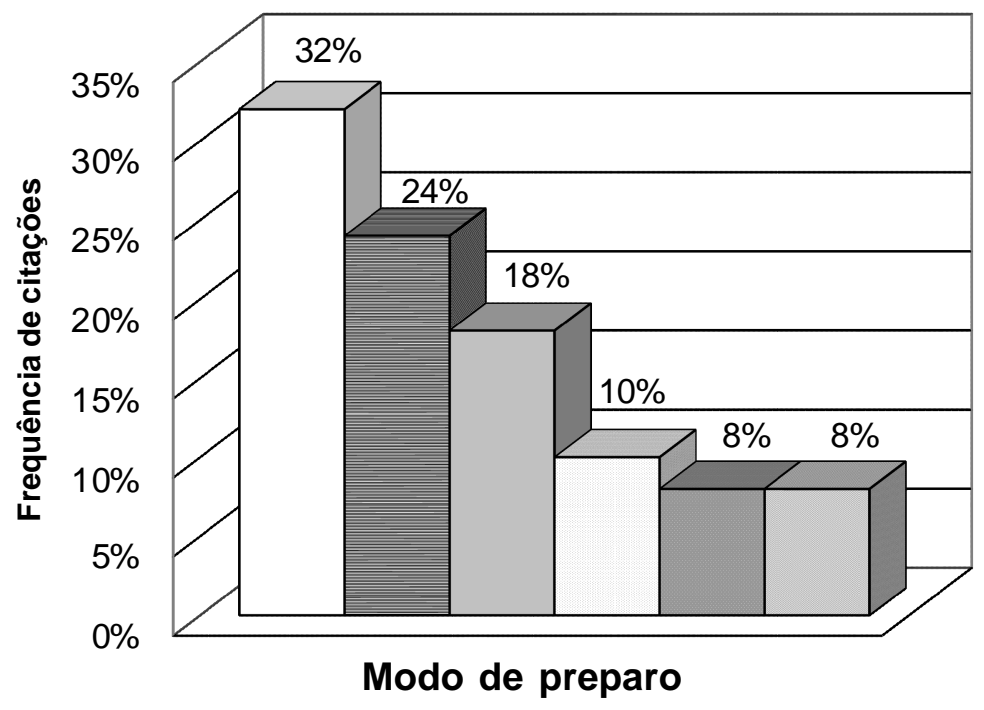

口Lambedor $\boldsymbol{\theta}$ Chá $\square$ Maceração $\square$ Banho de acento $\square$ Compressa $\square$ Outros

FIGURA 8. Modo de preparo de medicamento empregando espécies de plantas medicinais citadas pelos entrevistados do município de São José de Espinharas - PB.

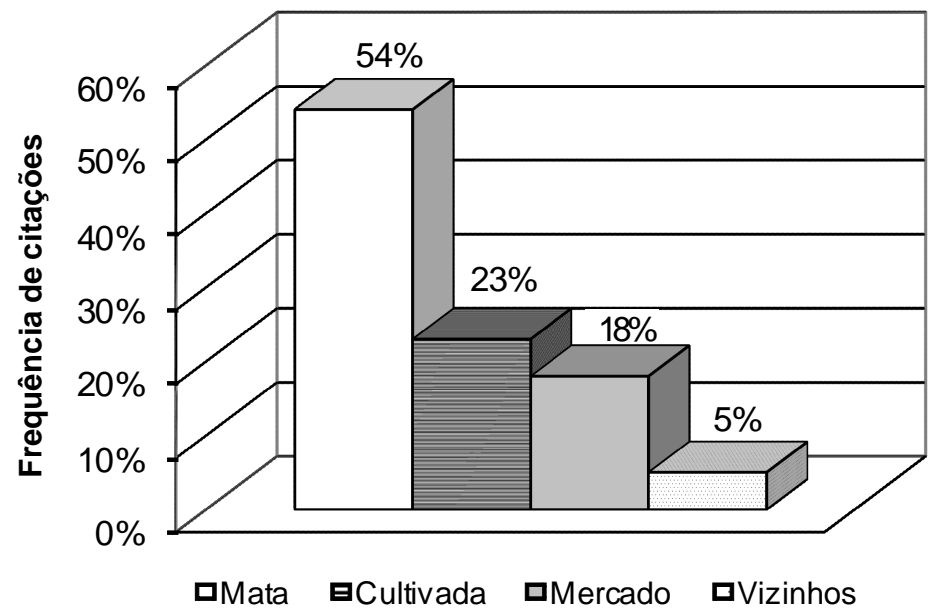

FIGURA 9. Procedência das plantas medicinais utilizadas pela comunidade de São José de Espinharas - PB. 


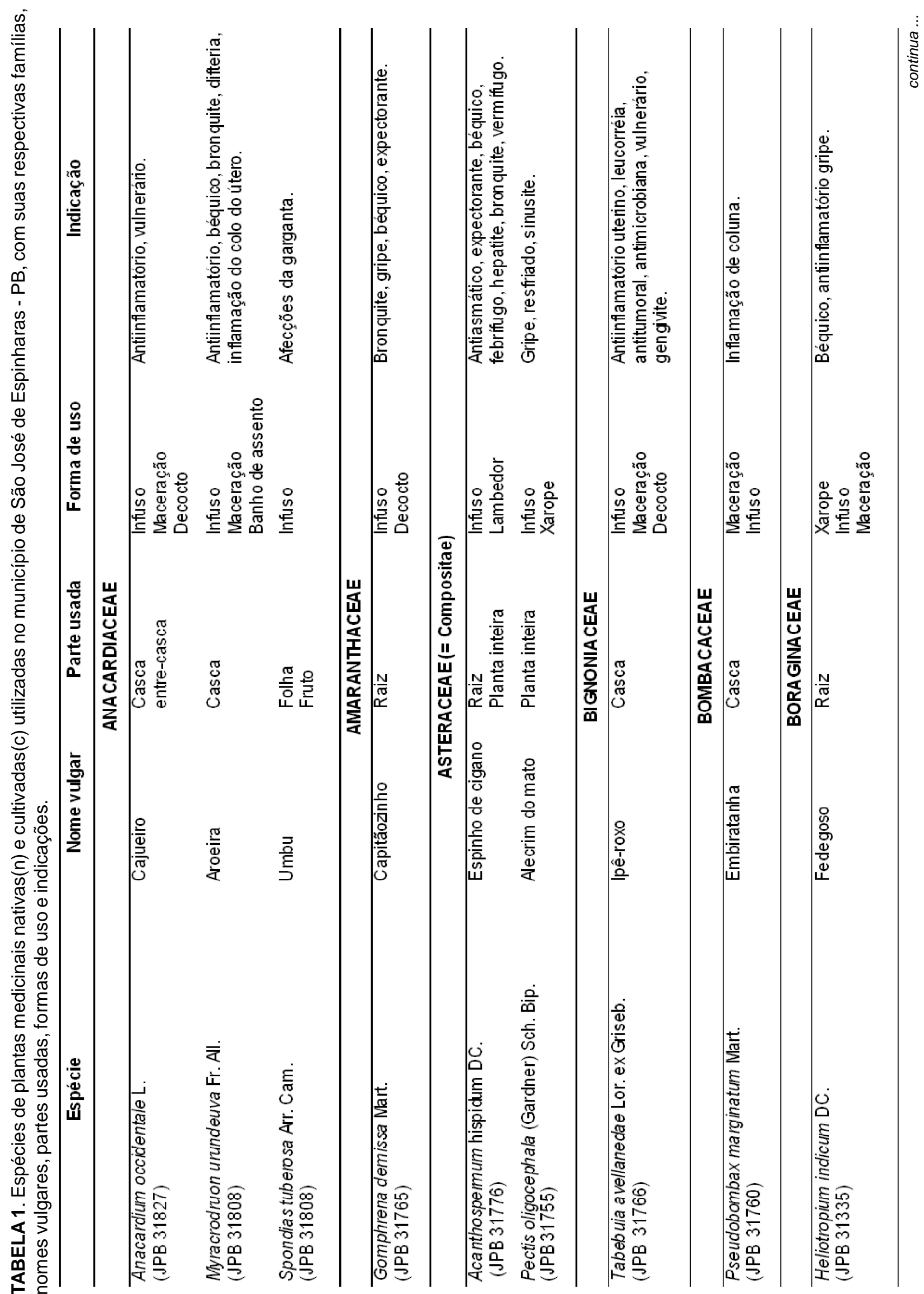




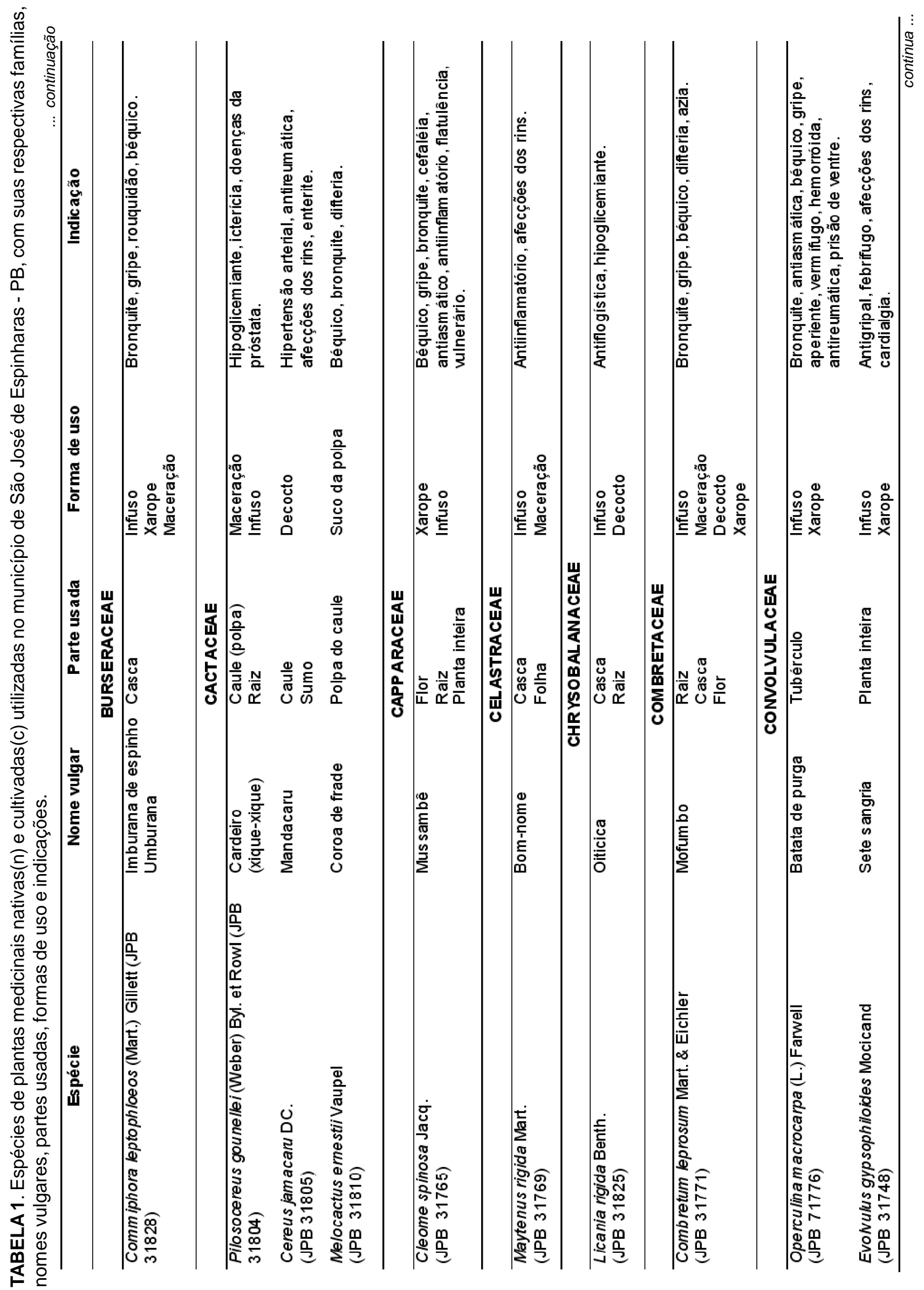




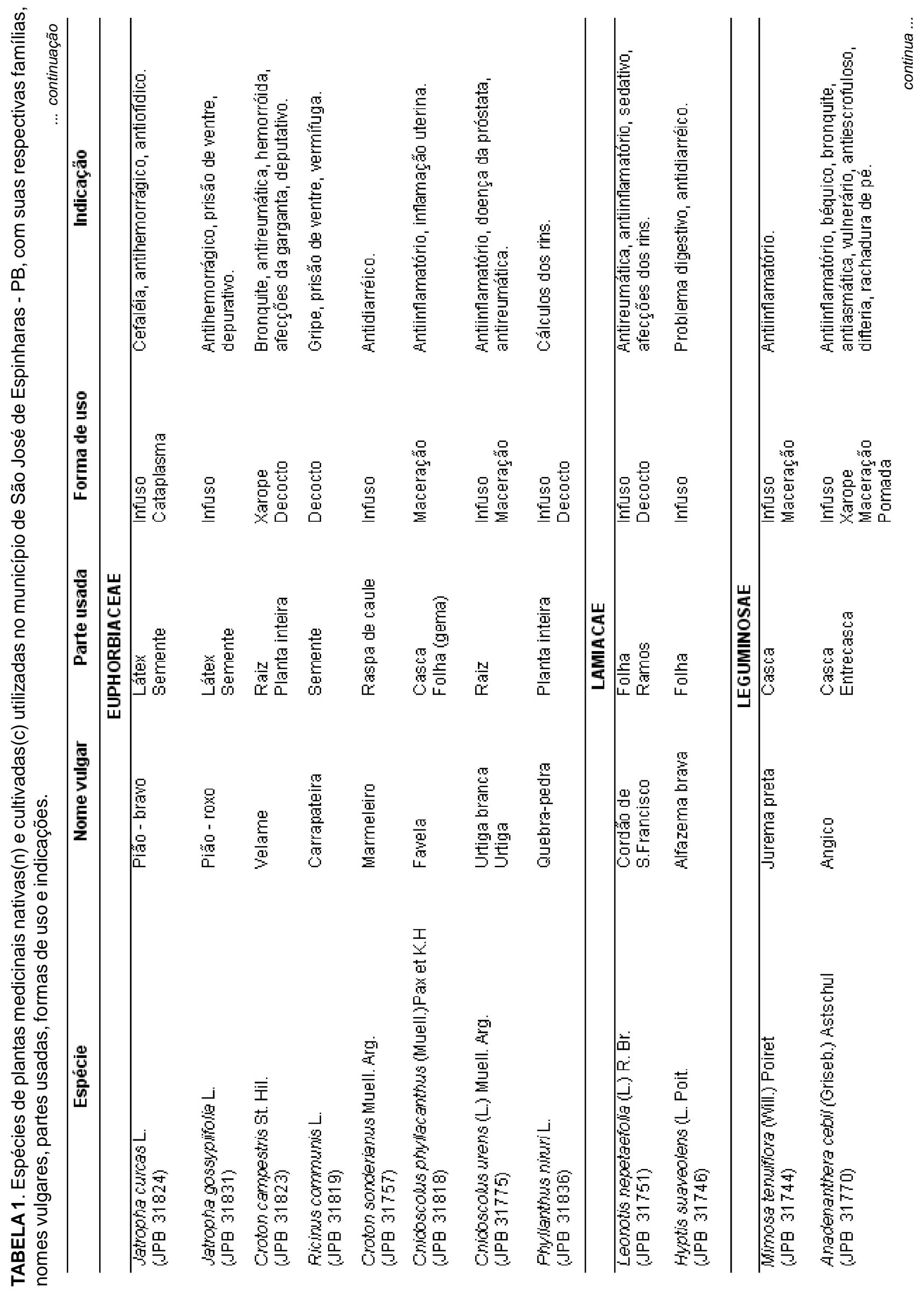




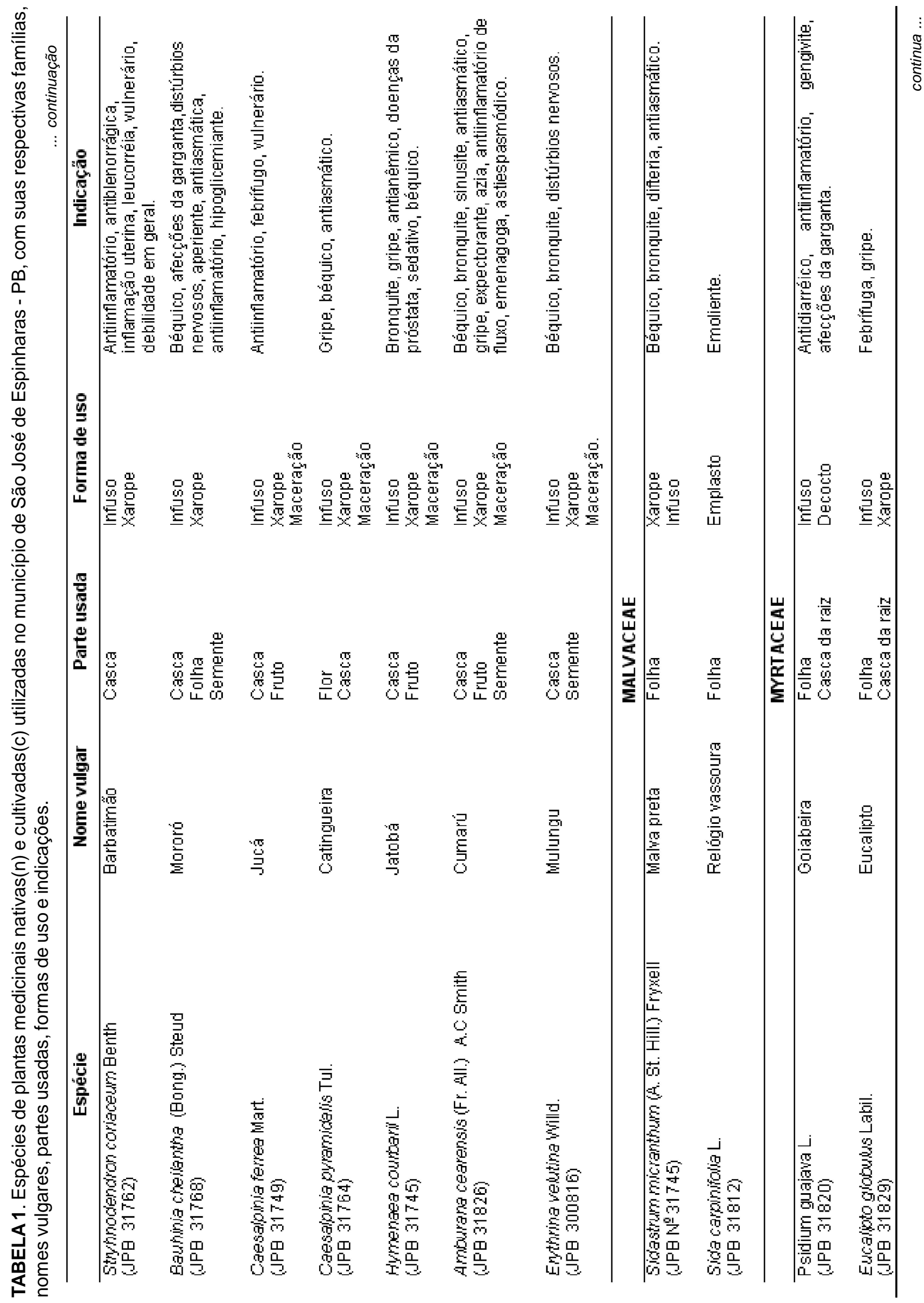

Rev. Bras. PI. Med., Botucatu, v.13, n.2, p.170-182, 2011. 


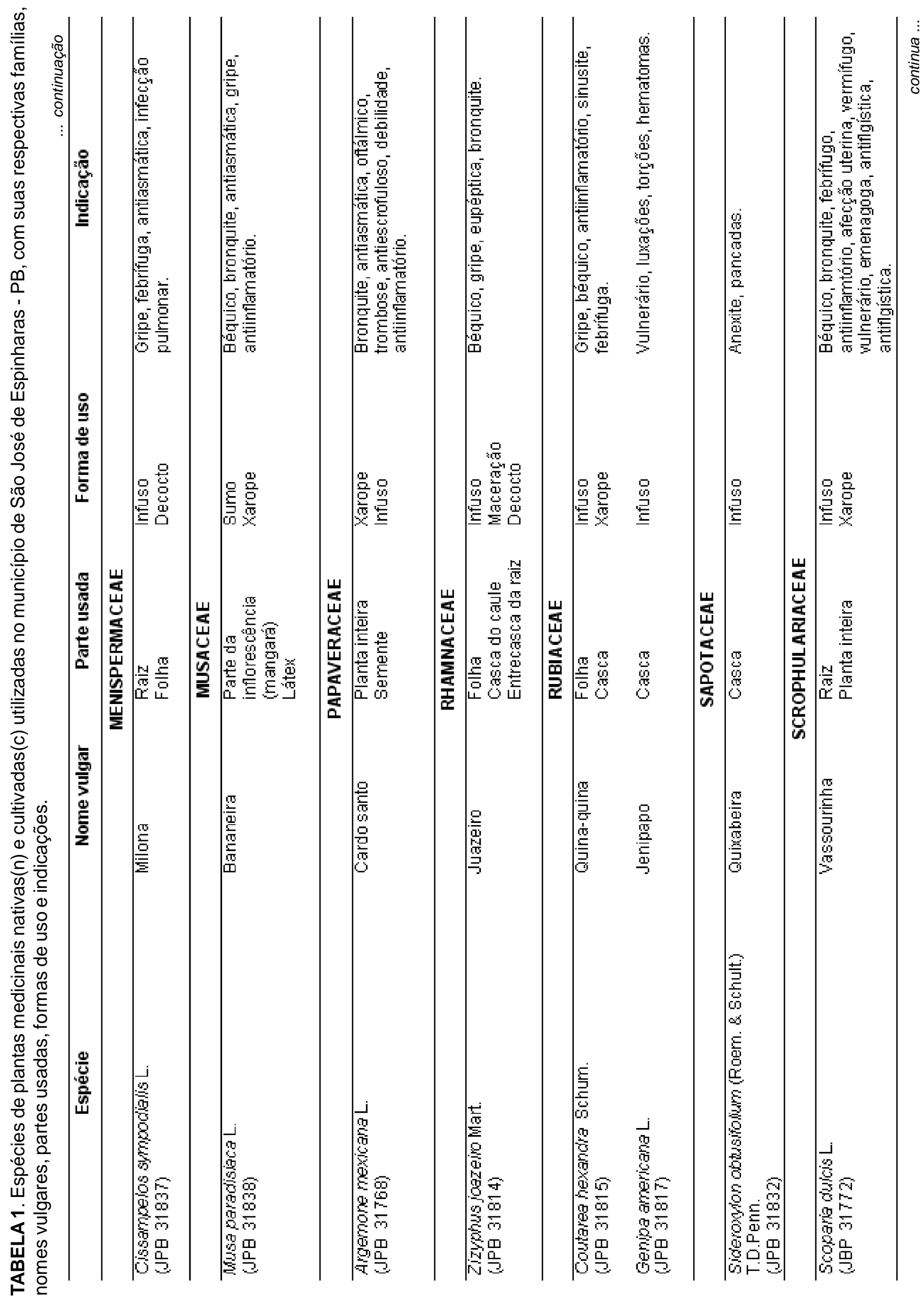




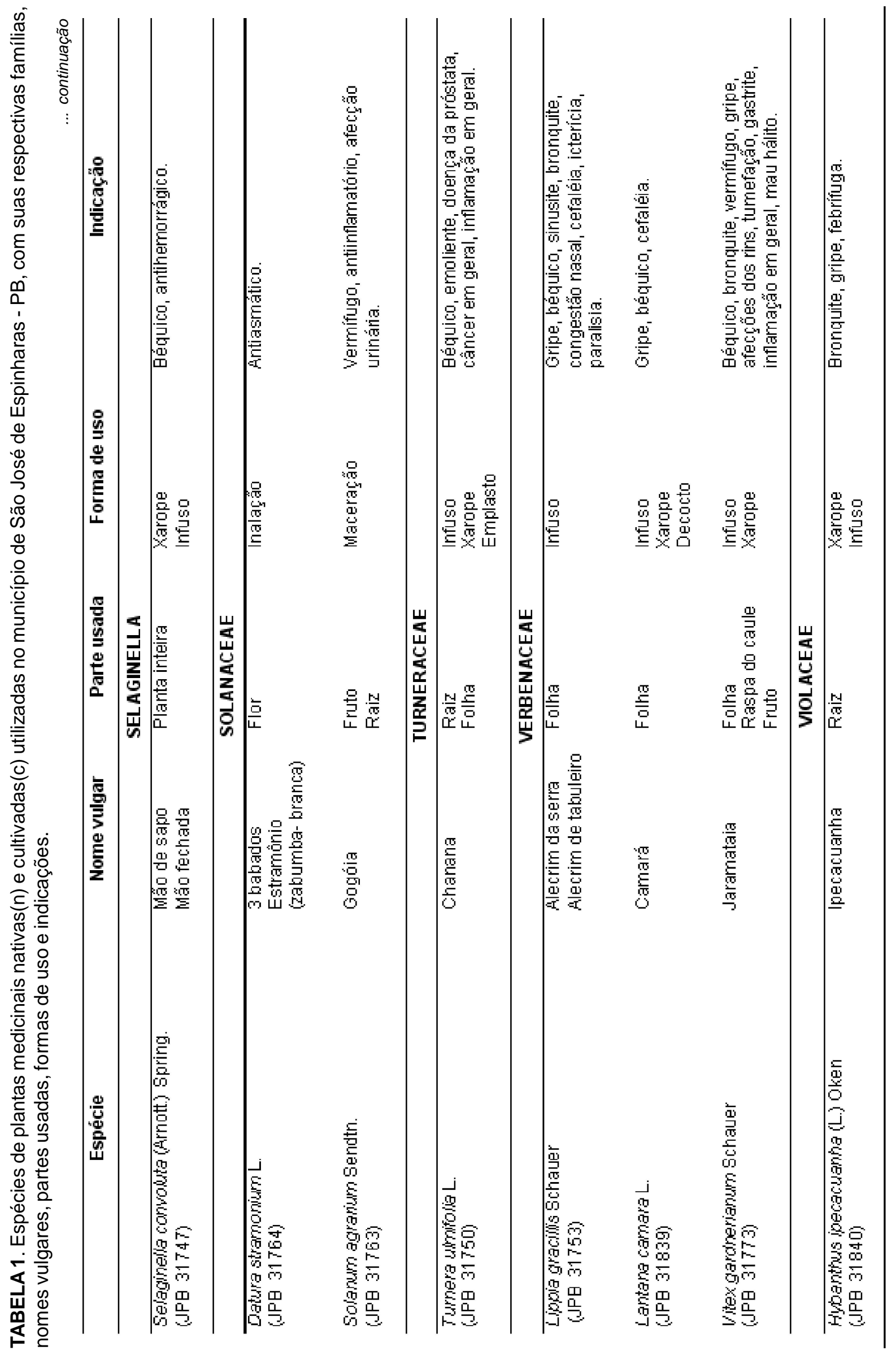

Rev. Bras. PI. Med., Botucatu, v.13, n.2, p.170-182, 2011. 


\section{CONCLUSÃO}

A flora medicinal no município de São José de Espinharas obteve uma grande representatividade com grande número de plantas medicinais nativas utilizadas e está associado á influência da cultura do antigo habitat dos índios Pegas e Panatis, que integraram a microrregião de Patos, no semi-árido paraibano.

Os informantes mais velhos, ao longo dos anos habitando a caatinga, desenvolveram uma capacidade muito própria de identificar as plantas, que inclui observações de aspectos morfológicos, químicos, de uso medicinal, ecológicos e culturais. Essa atividade é utilizada para busca de plantas na caatinga e indicação delas para outras pessoas. Muitos deles desenvolveram bastante essa capacidade, tornando-se conhecedores de diversas características da mata percebendo, inclusive, alterações significativas que podem indicar vulnerabilidade de algumas espécies. Essas informações são valiosas para estudos taxonômicos, ecológicos e químicos, como pode ser observado nos exemplos abaixo:

"Tem a jaramataia que é uma planta que dá nas margens de rio. Antigamente tinha muito, agora tem pouca"(Sítio Caicu, São José de Espinharas).

"A raiz da mangiroba serve para gripe e tosse. Você pega três raízes, três pé de mangiroba , três raízes de espinho de cigano e três dente de alho bota em uma vasilha com água e junta a 3 pedrinha em brasa, isto é chamado chá ferrado, receita de minha mãe. (Sítio Caicu, São José de Espinharas).

A forma de transmissão do conhecimento é feita por meio dos mais idosos, e isto fica claro nos depoimentos:

"...aprendi com os mais antigo e a gente vem seguindo naquilo."

"...Usá as plantas aprendi de vê e ovi otros falarem: avós, pais, parentes, vizinhos."

"...remédio busco na mata ou procuro aqui mesmo com os parentes."

De acordo com esses relatos, se observa o uso das espécies nativas para o preparo de medicamentos, sem deixar de citar as espécies cultivadas.

O amplo conhecimento sobre a flora utilizada na medicina caseira, leva a comunidade de São de Espinharas a acreditar que:

"Toda planta serve prá alguma coisa, é remédio, a gente é que não sabe."

"As vez, a gente tá pisando no remédio e não sabe."

Comparam os remédios caseiros com os vendidos em farmácias:

"Hoje as pessoas não usa mais mato, vão direto ao médico. As plantas é mais sadio, sai puro. O de farmácia é misturado".
Relatam sobre os efeitos colaterais:

"Os remédios com mato não contamina, por isso nós toma, porque falam que remédio de farmácia cura uma doença e faz adoencê de outra coisa".

"A casca de aroeira é pra fazê lavage em mulher (uterina) e também pode tomá um pouquinho. Não pode se usá em mulher com anemia".

A erva cidreira e o alecrim de serrote, pertencentes a um mesmo gênero ( $L$. alba (Mill.) N.E.Br. e L. gracilis Schauer), são distinguidas nas comunidades estudadas por meio de caracteres morfológicos e organolépticos e pelo uso. Essa diferenciação é coincidente entre os entrevistados:

"A diferença entre o alecrim de serrote e erva cidreira é o cheiro da folha. O alecrim de serrote é prá gripe, tosse, sinusite, bronquite e erva cidreira é prá dor de barriga, e acalmá". (Sítio Caicu, São José de Espinharas).

"O alecrim de serrote é parecido com a cidreira, só que que ela tem outra função. A cidreira é calmante e o alecrim de serrote serve para gripe $e$ resfriado" (C.A.F. , Sítio Caicu, São José de Espinharas).

Na preparação dos remédios caseiros todas as partes das plantas foram empregadas: raízes, cascas, folhas, flores, frutos e sementes. As cascas corresponderam ás partes mais utilizadas (38\%), em seguida vieram as folhas (27\%) e raízes (19\%).

Houve diversas formas no preparo dos remédios: Lambedor, chá, maceração, banho, e compressas. No entanto, o lambedor apresentou maior índice, seguido do chá (24\%).

Reproduziram-se as informações da maneira como foram coletadas, muitas vezes não houve especificamente distinção entre sintomas e doenças, como a citação "bom para o fígado e estômago", sugerindo diversas interpretações que podem estar associadas a dores, má digestão, congestão, gastrite, úlceras e ressaca alcoólica, porém todas relacionadas a problemas do sistema digestivo, como no caso da alfazema brava, jaramataia e marmeleiro. As citações como expectorante, sinusite, tosse, gripe, pontada e pneumonia foram associadas com problemas respiratórios, como no caso de angico, cumaru, mulungu, milona e quina-quina.

A maioria das plantas medicinais citadas pelos informantes, estão relacionadas com inflamação, como no caso de favela, urtiga branca, cordão - de - São Francisco, jurema preta, angico, catingueira, goiabeira, vassourinha e gogoia.

A troca de informação entre parentes, vizinhos e amigos faz com que a relação ser humanoflora se mantenha viva e este conhecimento seja repassado aos seus descendentes.

$O$ etnoconhecimento referente às plantas medicinais é repassado oralmente por meio das tarefas diárias, pelo exemplo dos mais velhos, sendo a mulher a responsável principal pela transmissão

Rev. Bras. Pl. Med., Botucatu, v.13, n.2, p.170-182, 2011. 
destes conhecimentos. Enquanto as crianças acompanham os pais nas lidas cotidianas, vão conhecendo as diferentes espécies medicinais empregadas no preparo dos medicamentos, as utilidades e os habitats.

A eficácia das plantas medicinais no tratamento de diversas doenças e o conhecimento sobre seu uso e preparo, transmitida de geração em geração de forma empírica, contribui para sua grande utilização por populações tradicionais. A geração anterior, nas comunidades estudadas, como ainda não mantinha maiores contatos com o atendimento primário de saúde da rede pública, tinha maior necessidade de uso de produtos da floresta (caatinga). Todos os entrevistados também afirmaram, sem precisar a idade, que desde criança ou "desde que me conheço por gente", iniciaram a observação e o uso das plantas medicinais.

Sabemos que há uma grande preocupação entre diversos pesquisadores em esclarecer aspectos relacionados á identificação e ao uso adequado das plantas medicinais. Neste trabalho, verificou-se que a população de São José de Espinharas utiliza a fitoterapia como forma de prevenção e cura de muitas doenças, relacionadas a sinais e sintomas apresentados. Portanto, surge a necessidade de estudos mais aprofundados que venham a integrar profissionais envolvidos principalmente em Etnobotânica, Etnofarmacologia e Fitoquímica, a fim de resgatar o conhecimento popular e analisar a composição química dos vegetais utilizados popularmente visando basicamente a busca de melhores condições de vida para o ser humano, através das plantas medicinais no seu respectivos ambientes.

\section{REFERÊNCIA}

AGRA, M.F. Contribuição ao estudo das plantas "medicinais" na Paraíba. In: SIMPÓSIO DE PLANTAS MEDICINAIS NO BRASIL, 6., 1980, Fortaleza, CE. Anais... Fortaleza: Sociedade Brasileira para o progresso da Ciência - SBPC, 1980. p.64-6.

AGRA, M.F. et al. Plantas medicinais dos Cariris Velhos, Paraíba. Parte I: Subclasse Asteridae. Revista Brasileira de Farmácia, v.75, n.3, p.61-4, 1994.

AGRA, M.F. et al. Plantas medicinais dos Cariris Velhos, Paraíba. Parte II: Subclasse Magnoliidae, Caryophylldae, Dlleniidae e Rosidae. Revista Brasileira de Farmácia, v.77, n.3, p.97-102, 1996.

ALBUQUERQUE, U.P. Etnobotânica no Nordeste Brasileiro. In: CAVALCANTI, T.B. (Org.). Tópicos atuais em Botânica: Congresso Nacional de Botânica. 51., 2000. Anais ... Brasília: Embrapa, p.241-9. 2000.

ALBUQUERQUE, U.P.; ANDRADE, L.H.C. Conhecimento botânico tradicional e conservação em uma área de caatinga no Estado de Pernambuco. Acta Botânica Brasílica, v.16, n.3, p.273-85, 2002.

AMOROZO, M.C.M. Abordagem etnobotânica na pesquisa de plantas medicinais. In: Di STASI, L.C. (Org.). Plantas medicinais: arte e ciências - um guia de estudo interdisciplinar. São Paulo: UNESP, 1996. p.47-68.

BRAGA, R. Plantas do Nordeste especialmente do Ceará. Fortaleza: Imprensa Oficial, 1976. 540p.

DORIGONI, P.A. et al. Levantamento de dados sobre plantas medicinais de uso popular no município de São João do Polêsine, RS, Brasil. I - Relação entre enfermidade e espécies utilizadas. Revista Brasileira de Plantas Medicinais, v.4, p.69-79, 2001.

FORMAN, L.; BRIDSON, D. The herbarium handbook. Kew Great Britanic: Royal Botanic Garden,1989. 214p.

GUARIM-NETO, G.; SANTANA, S.R.; SILVA, J.V. B. Notas etnobotânicas de espécies de Sapindaceae Jussieu.

Acta Botanica Brasilica, v.14, n.3, p.327-34, 2000.

IBGE. São José de Espinharas. São José de Espinharas, 1997. (Coleção de monografias municipais. Nova série, 206.)

LORENZI, H. Árvores brasileiras: manual de identificação e cultivo de plantas arbóreas nativas do Brasil. São Paulo: Plantarum, 1992. 371p.

LORENZI, H. Manual de identificação e controle de plantas daninhas: plantio direto e convencional. São Paulo: Plantarum, 1994. 299p.

LORENZI, H. Árvores brasileiras: manual de identificação e cultivo de plantas arbóreas nativas do Brasil. São Paulo: Plantarum, 1998. 352p.

LORENZI, H.; SOUZA, H.M. Plantas ornamentais no Brasil: arbustivas, herbáceas e trepadeiras. São Paulo: Plantarum, 1995. 720p.

MATOS, F.J.A. As plantas das farmácias vivas; álbum de gravuras para identificação das principais plantas medicinais do projeto farmácias vivas. Fortaleza: BNB, 1997. 57p.

MATOS, F.J.A. Farmácias vivas: sistema de utilização de plantas medicinais projetado para pequenas comunidades. 3.ed. Fortaleza: UFC, 1998.179p.

MING, L.C.; AMARAL JUNIOR, A. Aspectos etnobotânicos de plantas medicinais na Reserva Extrativista "Chico Mendes". 1995. 180p.Tese (Doutorado em Botânica) Departamento de Botânica, Instituto de Biociências, UNESP, Botucatu.

SHELDON, J.W.; BALICK, M.J.; LAIRD, S.A. Medicinal Plants: can utilization and conservation coexist? New York: New York Botanical Garden, 1997. 104p. 